\title{
Innovative method for training students to develop enterprising, decision-making and cooperation skills through complex computer- networks team-design
}

\author{
Petre-Daniel Mătăsaru*, and Luminița Scripcariu \\ Technical University "Gheorghe Asachi" of Iasi, Faculty of Electronics, Telecommunications and \\ Information Technology, 11 Carol I Blvd., Iasi, Romania
}

\begin{abstract}
Our paper presents a short overview of the educational methods used in the learning process in telecommunication domain, targeting skills and competences students acquire and develop during the semester and focusing on the ones that are most valuable and appreciated on the labor market after graduation. Our research of the market shows that besides basic engineering knowledge, skills like initiative, team-playing, business analysis, decision-making, marketing and creative project presentation are considered very valuable assets by HR recruiters. We implement and test an improved method that combines classic techniques with the use of modern digital tools, emphasizing on specific tasks that coach the student how to deal with real markets, extract valuable data through analysis, design up-to-date computer-networks, make correlated decisions based also on economic arguments, team working and assume responsibilities. This is achieved through a real-case study and project themes for computer-networks that involve real situations with technical and budgetary challenges, market analysis and research through online facilities and dealing with specialized software for network design and simulation with a creative presentation. The presented approach is intended to prepare faculty staff to implement innovative and self-improving teaching methods in engineering educational process and thus make an educational reform happen [1].
\end{abstract}

\section{Introduction}

Most instructional methods used in the learning process in the electronics, telecommunication and information technology domain are consisting of a combination of core elements of active, collaborative, cooperative and problem-based learning [2]. In engineering literature, collaborative learning may be referring to any type of educational method that makes the students work together in small teams in order to reach a common goal [3], cooperative learning may be a particular form of collaborative learning where students also work in teams to achieve common goal, but they are assessed individually [4-

\footnotetext{
* Corresponding author: dmatasaru@etti.tuiasi.ro
} 
5] and problem-based learning may represent an educational method where specific problems are used to provide context and motivation for the learning that follows, involving significant amounts of self-oriented learning effort on the student side [2].

While the above mentioned three techniques are universal and represent a common ground for all university staff with a technical background, active learning makes a difference, engaging students in the learning process by requiring them to do meaningful activities, get quantitative and qualitative results and acknowledge their contribution. The presented training process aims improving skills of both students, and teaching staff.

\section{Quick overview on the graduate employ-ability skills}

Many studies on Higher Education in Europe reveal the fact that both employers and future employees graduate identify several key soft skills and competences integral to the employment process.

According to Andrews and Higson [6], among these is the ability to plan and think strategically, the capability to communicate and interact with others, either in teams or through networking, good written and verbal communication skills, Information and Communication Technology skills, creativity, good self-management and timemanagement skills. Furthermore, these key features may form the basis and main values of current employment interviews.

Others [7] emphasize on the need of engineering schools to strengthen their coverage of fundamentals, teach a more realistic and up to date engineering design and operations, including quality management, provide student training in critical and creative thinking skills, with good engineering ethics within the development of technology.

Without regard to the identified types of skills, three important themes stand up, each of them focusing on various components of graduate employability: Business Specific Issues referring to Hard business-related knowledge and skills, Interpersonal Competencies referring to Soft business-related skills and Work Experience and Work-Based Learning. [6]

From the employer point of view, the added-value of employing an engineering graduate with enterprising skills may be that a superior level business approach represented more than just simple evidence of getting and applying knowledge, it also reflected the individual's ability to think in a critical and applied manner to the economic environment. A plus may be given also by the fact that engineering graduates with good decision making skills require less supervision and mentoring, are more mature and fit sooner into their working environment.

From the graduate point of view, a mixed approach of studying both in terms of engineering and economics may be considered positive in achieving more business-focused skills for their portfolio that would provide better employment chances. However, studies point out for the graduates' perspective that even though many of them feel confident in respect of knowledge focused abilities, they perceive themselves as lacking the necessary level of presentation skills [6].

\section{Improved training method: designing, testing and presenting a real-case computer network as a student-team enterprise}

The instructional method that we apply comes as a response to the labor market needs according to various studies and our own research made through meetings, discussions and collaborations with representatives of national and international companies in the electronic, telecommunications and Information Technology domain. It is, in fact, a 
solution that emphasizes on the interaction of students and the business environment in groups with focus on the practical issues instead of the classical individual theoretical learning. Thus, besides the basic engineering knowledge that most of the students/graduates get through classical educational process, skills like initiative, team-playing, business analysis and decision-making, marketing and creative results presentation are also targeted.

Our method combines classic instructional techniques with the use of modern digital and online tools, focusing on specific tasks that coach the student on how to deal with the real market, extract valuable data through analysis and data-mining, design up-to-date computer-networks, make correlated decisions based not only on technical issues but also on economic arguments, work in a team and assume responsibilities and finally, present in an attractive manner the results of the teamwork.

This is achieved through a real-case study and project themes for computer-networks that involve real situations with technical and budgetary challenges, market analysis and research through online facilities and dealing with specialized software for network design, network simulation and creative presentation.

Project evaluation is made in an innovative way. Students must evaluate the projects of their colleagues from the entrepreneurial point-of-view as possible beneficiaries. They have to select the best project as a compromise between technical and economic aspects. This contest motivates students to improve their entrepreneurial and argument-based decisionmaking skills.

\subsection{Creating work groups and choosing the theme of the project}

Cooperative learning models involve the creation of working groups by the coach and our method does not cross the line in this matter. Then group members choose a team-leader by consensus. What we are doing different is to choose the theme of the project based on the common background of the students that are part of the working group. Thus, students are more responsible with their project since they are involved in the decision process and are better motivated to study and work harder as a team because they feel like belonging to the project and the results of their work will be closer to the real technical and economic environment on a real-case study.

For example, student work groups' choices are computer network design, testing and implementation for their home high-school, public libraries in their home cities, companies where they had internships, various types of private businesses like newspapers, internetcafes, call-centers and restaurants where they had part-time jobs as students.

\subsection{Changing perspective from a school project to a student enterprise}

After setting the working groups and the theme of the project, the next step is to approach the project from the business point of view, students becoming "virtual entrepreneurs" and forced this way to get acquainted to concepts like market research, data mining, human resources cost, material costs, project budget, communication and PR, besides the technical aspects of a computer-network design.

Within the project students are required to create a "costumer chart" with general information about the type of activity, company estimated number of employees, offices and organizational chart, current and future development plans. Based on this "costumer chart", the design of the project begins.

The next step is to effectively design the computer network, establishing the location of the computers in the building, the connections diagram, the physical and logical topology, the necessary sub-nets number depending on the departments of the beneficiary company 
(see figure 1), the hosts' IP addresses per each sub-net (see table 1), and the required security levels.

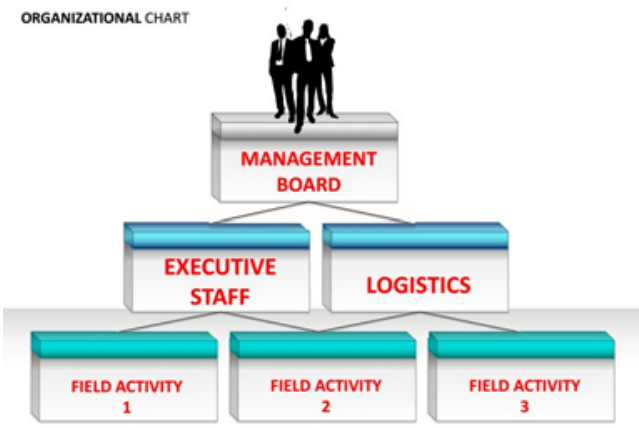

Fig. 1. Organizational chart of a "project beneficiary".

Decisions have to be made in order to meet the optimal solutions for all problems, so the students in the working group not only have to collaborate, but also to face their colleagues' suggestions, analyze them and, if necessary, sustain with arguments the better outcome.

Table 1. Example of IP allocation table

\begin{tabular}{|c|c|c|c|c|}
\hline Sub-net & Sub-net Mask & & IP & Default Gateway \\
\hline \multirow{3}{*}{ S\#1 } & \multirow{3}{*}{255.255 .255 .224} & $\mathrm{H} \# 1$ & 192.168 .1 .34 & \multirow{3}{*}{ 192.168.1.33 } \\
\hline & & $\mathrm{H} \# 20$ & 192.168 .1 .53 & \\
\hline & & $\mathrm{H} \# 30$ & 192.168 .1 .62 & \\
\hline \multirow{3}{*}{$\mathrm{S} \# 2$} & \multirow{3}{*}{255.255 .255 .224} & $\mathrm{H} \# 1$ & 192.168 .1 .66 & \multirow{3}{*}{ 192.168.1.65 } \\
\hline & & $\mathrm{H} \# 20$ & 192.168 .1 .85 & \\
\hline & & $\mathrm{H} \# 30$ & 192.168 .1 .94 & \\
\hline \multirow{3}{*}{ S\#3 } & \multirow{3}{*}{255.255 .255 .224} & $\mathrm{H} \# 1$ & 192.168 .1 .98 & \multirow{3}{*}{ 192.168.1.97 } \\
\hline & & $\mathrm{H} \# 20$ & 192.168.1.117 & \\
\hline & & $\mathrm{H} \# 30$ & 192.168 .1 .126 & \\
\hline \multirow{3}{*}{$\mathrm{S} \# 4$} & \multirow{3}{*}{255.255 .255 .224} & $\mathrm{H} \# 1$ & 192.168 .1 .130 & \multirow{3}{*}{ 192.168.1.129 } \\
\hline & & $\mathrm{H} \# 20$ & 192.168.1.149 & \\
\hline & & $\mathrm{H} \# 30$ & 192.168 .1 .158 & \\
\hline \multirow{3}{*}{$\mathrm{S} \# 5$} & \multirow{3}{*}{255.255 .255 .224} & $\mathrm{H} \# 1$ & 192.168 .1 .162 & \multirow{3}{*}{ 192.168.1.161 } \\
\hline & & $\mathrm{H} \# 20$ & 192.168.1.181 & \\
\hline & & $\mathrm{H} \# 30$ & 192.168 .1 .190 & \\
\hline
\end{tabular}

Once every technical aspect is determined, the following step is to implement, configure and test the computer network using specialized engineering software.

In the end, after the completion and validation of all required tests concerning technical issues, an estimation of costs per chapters and overall budget has to be made.

For this, students are asked to search individually the web for network components and other material prices and calculate, from an economic point of view, a reasonable close to reality cost of the entire project. Other decisions, this time, economical, have to be made, after a comparison between the prices at working team level.

An example of overall budget calculus is given below:

UTP Cable CAT5e: $1000 \mathrm{~m} * 0.99 \mathrm{RON} / \mathrm{m}=990 \mathrm{RON}$;

Switch (Switch Allied Telesis AT-GS950/24):4 * 1,630 RON = 6,520 RON;

Router (Router Linksys Cisco RV082-EU): 2 * 2,024 RON = 4,048 RON;

RJ-45 Connectors: $200 * 0.2 \mathrm{RON}=40 \mathrm{RON}$.

Cable channels $(80 \times 60,200 \mathrm{~m}): 1,500 \mathrm{RON}$.

Server (Server HP Tower ML110 G7): 2,259 RON. 
Students also calculate the labor costs based on an estimation of working hours and workers' qualification. For example, for this project, the labor costs are evaluated to 10,000 RON.

Thus the TOTAL AMMOUNT results as 26,257 RON.

\subsection{Improving presentation skills}

A final objective of our instruction technique is to improve the student's presentation skills by requesting that the entire project to be presented in front of all the other teams in a modern manner and a time limit.

The presentation should be made using an online tool like Prezi [8] and every member has to present a part of the group project. Thus, cooperation and presentation skills are improved; focus is put also on other relevant features for the employer like creativity, responsibility, good time-management and the opening to new technologies. Project presentation includes the network simulation (see figure 2) and testing (see figure 3).

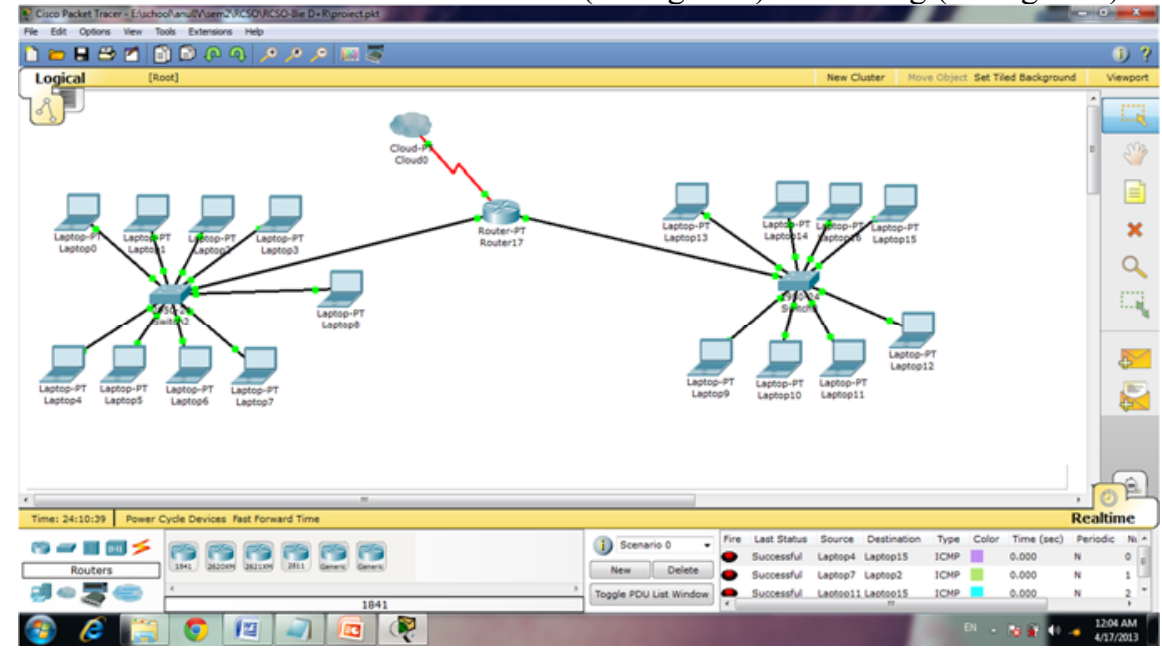

Fig. 2. Implementation, configuration and testing of the computer network design.

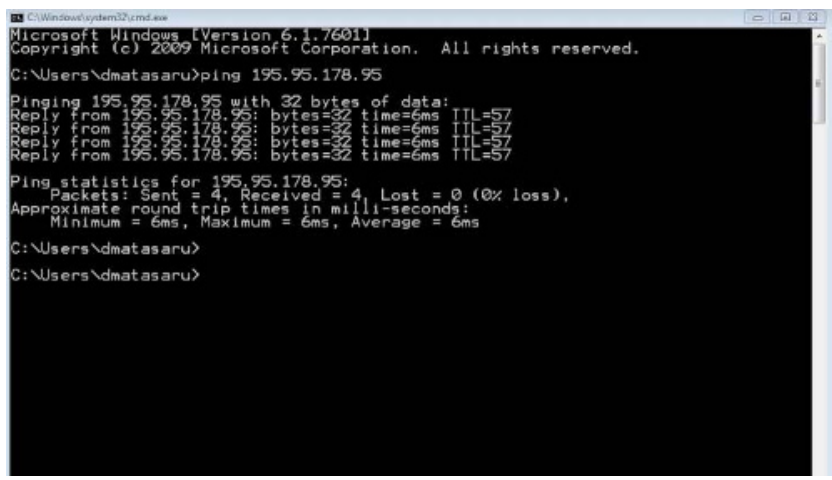

Fig. 3. Connectivity Testing in Command Prompt.

\subsection{Developing entrepreneurial skills}

After all projects are presented, each student evaluates them, from the investor's point-ofview, and chooses three projects that he appreciates to be very well done and economically 
justified. Comparing their project with the others, students become aware of the strong points and the weak points of their own project.

\subsection{Project evaluation}

A polling session is organized and after the count of votes, one project is declared as eligible to be financed and communicated to the auditorium.

This final activity imposes another kind of responsibility to students. They are not implicated as technical staff but they act as investors so their entrepreneurial skills are developed.

The teacher acts as a neutral moderator during the presentation of the projects, leaving the decision on the best project to be made by the students.

In the same time, the projects are technically evaluated by the teacher himself without knowing the student polling result.

Finally the teacher evaluation results and the polling result are confronted. This is the moment when the righteousness of students' decision is analyzed.

\section{Conclusions}

Our model incorporates both classic instruction techniques and business-oriented methods with the use of digital tools and could be categorized as active learning. The final objective is to enable, in an innovative way, the graduated student to be properly prepared for the labor market and the employer to be satisfied with the quality of the future employees simultaneously with training skills improvement of the training staff.

Both technical and economic knowledge, as well as initiative, strong decision-making abilities and the capacity to properly present the results of the work represent an important asset for any engineering company.

Last, but not least, the professional experience that students get while working on the computer-network design represents an added value for anyone's portfolio when applying for a job and sustaining a job interview.

The overall experience is valuable for both students and teacher.

\section{References}

1. R.M. Felder, J.E. Stice, A. Rugarcia, The future of engineering education, VI. Teaching methods that work, Chem. Engr. Education, 34, 3, 208-215 (2000)

2. M. Prince, Does Active Learning Work? A Review of the Research, Journal of Engineering Education, 93, 3, 23-231 (2004)

3. Online Collaborative Learning in Higher Education, http://clp.cqu.edu.au/glossary.html (accessed 12/3/2003)

4. B. Millis, P. Cottell, Jr., American Council on Education, Cooperative Learning for Higher Education Faculty (ORYX Press, 1998)

5. P. Feden, R. Vogel, Methods of Teaching: Applying Cognitive Science to Promote Student Learning (McGraw Hill Higher Education, 2003)

6. J. Andrews, H. Higson, Higher Education in Europe, Graduate Employability, 'Soft Skills' Vs 'Hard' Business Knowledge: A European Study, 33, 4, 411-422 (2008)

7. R. M. Felder, D. R. Woods, J. E. Stice, A. Rugarcia, Chem. Engr. Education, The future of engineering education. II Teaching methods that work, 34, 1, 26-39 (2000)

8. http://www.prezi.com 